\title{
25 Research Square \\ Root Responses To Neighbors Depend On Neighbor Identity And Resource Distribution
}

Tara K. Rajaniemi ( $\nabla$ trajaniemi@umassd.edu )

University of Massachusetts Dartmouth https://orcid.org/0000-0003-2861-3901

Kelsey Garlick

University of Massachusetts Dartmouth

Robert E. Drew

University of Massachusetts Dartmouth

\section{Research Article}

Keywords: soil heterogeneity, plant competition, qPCR, root foraging precision, root responses to neighbors

Posted Date: April 16th, 2021

DOI: https://doi.org/10.21203/rs.3.rs-390629/v1

License: (c) (1) This work is licensed under a Creative Commons Attribution 4.0 International License.

Read Full License

Version of Record: A version of this preprint was published at Plant and Soil on July 22nd, 2021. See the published version at https://doi.org/10.1007/s11104-021-05083-9. 


\section{Abstract}

Purpose: In a complex soil environment, competitive and environmental factors will interact with individual traits to influence a plant's root growth patterns and ability to compete for resources. Here, we examine how root growth of a focal plant, Plantago lanceolata L., responds to resource heterogeneity and to presence of two neighbor species, Centaurea jacea L.and Poa pratensis L.

Methods: A full factorial experiment tested the effects of nutrient heterogeneity, neighbors, and their interaction on root responses of Plantago. Roots in shared quadrants of a pot were harvested and quantified by qPCR for plants grown alone or with a neighbor, in patchy or even soil. The effects of experimental treatments on Plantago root mass distribution were tested with two-way ANOVA.

Results: When soil resources were evenly distributed, Plantago individuals increased root allocation to soil shared with a Centaurea neighbor but not a Poa neighbor. When soil resources were patchy, Plantago responded more strongly to Poa than to Centuarea, and placed more roots in the high-resource patch.

Conclusions: These results demonstrate that plants can respond differently to neighbors depending on species and that integrating multiple cues results in non-additive effects on root behavior.

\section{Introduction}

Plants are able to detect various cues from their environment both above and below ground (de Kroon et al. 2009; Cahill and McNickle 2011), and their responses to those cues can determine competitive outcomes and ultimately community structure (Fransen et al. 2001; Mommer et al. 2012; Padilla et al. 2013; Oram et al. 2018). Belowground, roots are known to respond to water, nutrients, chemicals, microbes and the roots of neighbors (reviewed by Cahill and McNickle 2011). In a complex soil environment, the combination of cues present, as well as individual traits and plasticity, will influence a plant's overall root growth patterns and its ability to compete for resources (Craine and Dybzinski 2013; Pierik et al. 2013).

Root responses to spatial variation in soil nutrients are well documented. Plants are capable, to varying degrees, of responding to spatial heterogeneity in nutrient availability (Johnson and Biondini 2001; Kembel and Cahill 2005). Plants tend to proliferate more roots in higher nutrient locations, which then can lead to increased nitrogen uptake and increased biomass (Hodge 2004; Mommer et al. 2012). Species vary in their foraging precision, the degree to which they grow roots selectively in nutrient-rich patches (Johnson and Biondini 2001; Grime and Mackey 2002; Ravenek et al. 2016). Potential patterns in this variation and its adaptive significance are debated (Kembel and Cahill 2005; Grime 2007; Kembel et al. 2008).

Plants also respond to the presence of neighbors, independent of their response to nutrients (Cahill et al. 2010; Belter and Cahill 2015). Three categories of responses have been observed: over-production, neighbor avoidance, or neutral (Cahill and McNickle 2011). Multiple studies have shown root over- 
production in response to neighbors (e.g. Gersani et al. 2001; O'Brien et al. 2005), avoidance of root overlap with neighbors (reviewed by Schenk et al. 1999; Pierik et al. 2013), or found both responses (e.g. Mommer et al. 2012). McNickle and Brown (2014) showed that the response of Brassica rapa plants to neighbors could be explained by their effects on soil resources.

Variation in response to neighbors is also not well understood. A great deal of debate has focused on elements of experimental design (reviewed by Chen et al. 2012), rather than traits of species or aspects of the environment. Comparative studies have shown both that species differ in root growth responses to competitors, and that those responses are dependent on the identity of the neighbor (Semchenko et al. 2007; Belter and Cahill 2015; Paya et al. 2015; Sattler and Bartelheimer 2018). Furthermore, neighbor identity effects are not consistent among focal species (Semchenko et al. 2007; Belter and Cahill 2015; Sattler and Bartelheimer 2018).

A few studies have investigated plant responses to the two simultaneous cues of resource heterogeneity and neighbors, but no consistent patterns have emerged. Addition of soil nutrients has been observed to shift the response to neighbors from neutral to over-production (Sattler and Bartelheimer 2018), from over-production to neutral (McNickle et al. 2016), from avoidance to neutral (Cahill et al. 2010), or from avoidance to greater avoidance (Nan et al. 2013). The interactive effects of resources and neighbors become even more complex when additional cues are introduced (e.g. earthworms, Wang et al. 2020)

In order to understand how plants integrate information about multiple cues and why responses vary, we need to better understand how plant traits and environmental variables drive those responses. A game theoretic model of root competition (McNickle and Brown 2012) offers some testable predictions. Previous models used game theory to predict that plants will over-produce roots in soil shared with neighbors (Gersani et al. 2001; O'Brien and Brown 2008). McNickle and Brown (2012) modified the game theory model to keep total soil volume constant for plants with or without neighbors, as in most competition experiments, and to allow the competing plants to differ in traits. Their model predicts that plants will generally over-produce roots when a neighbor is present, and that overproduction will be greater when resources are high. When neighbor traits differ, a plant with low cost of producing roots and high uptake rate should overproduce roots to preempt resources, whereas a plant with costly roots and low uptake rate should conserve resources and produce fewer roots.

Here, we test some of those predictions by examining root responses of Plantago lanceolata to nutrient heterogeneity, the presence of two different neighbors, and the combination of the two cues. Based on the results of the McNickle and Brown model, we predict that

(1)Plantago will respond to a neighbor by increasing root growth in shared soil.

(2)The response to a neighbor will be greater when the neighbor has traits associated with a greater cost of root production. 
(3) In heterogeneous soil, the response to a neighbor will be greater in a nutrient-rich patch than in a nutrient-poor patch, resulting in greater foraging precision when a neighbor is present.

Measuring root production in the presence of neighbors requires a method to determine each species' abundance in mixed samples of roots. Recently, DNA-based methods (Mommer et al. 2008) to quantify roots in mixed-species samples have been successfully applied in plant competition experiments (Mommer et al. 2012; Hendriks et al. 2015; Ravenek et al. 2016; Oram et al. 2018). Here, we modify that approach to develop species-specific DNA markers for each of our study species and apply those markers to test the predictions above.

\section{Materials And Methods}

\section{Study species}

Our study species are grassland perennials that co-occur in old fields on the UMass Dartmouth campus $\left(41.6309^{\circ} \mathrm{N}, 71.0067^{\circ} \mathrm{W}\right)$. Plantago lanceolata L., our focal plant, is a perennial forb. In previous studies, this species has exhibited foraging precision (Wijesinghe et al. 2001; Maestre and Reynolds 2007; Mommer et al. 2010) and over-production with neighbors (Mommer et al. 2010; Padilla et al. 2013). Two species with contrasting traits were chosen as neighbors. Centaurea jacea L., a forb, has a lower specific root length than Plantago and a greater concentration of $\mathrm{N}$ and $\mathrm{P}$ in its roots, while Poa pratensis $\mathrm{L}$. a grass, has greater specific root length than Plantago and a lower root concentration of $\mathrm{N}$ and $\mathrm{P}$ (data from Schroeder-Georgi et al. 2016; Ravenek et al. 2016; Herz et al. 2017; as published in the Global Root Traits database, Guerrero-Ramirez et al. 2020). Both neighbors have higher root N uptake rates than Plantago (Schroeder-Georgi et al. 2016).

\section{Marker development and validation}

We developed species-specific DNA markers for the three species in the current study using a strategy similar to that of Mommer et al. (2008). However, instead of using the ISSR approach to randomly sample the genomes of target species for sequences flanked by microsatellites, we adapted AFLP methods (Vos et al. 1995) to sample sequences flanked by specific restriction enzyme sites. This approach allows the option of sampling different sets of sequences by changing the restriction enzymes. We found this to be an effective alternative but did not empirically evaluate it in comparison to the ISSR approach.

Briefly, $200 \mathrm{ng}$ of genomic DNA from each species was digested with Hpall and EcoRI restriction enzymes (New England Bio Labs, Ipswich MA), and AFLP libraries were prepared following Blouin et al. (2010). After the PCR amplification step, the AFLP libraries were cloned using the TOPO TA Cloning Kit for Sequencing (Thermo-Fisher Scientific, Grand Island NY), following the manufacturer's recommended procedure. For each species, 15-30 colonies, each containing one fragment insert, were randomly selected and sequenced using standard M13 primers at the MGH CCIB DNA Core facility (Massachusetts General Hospital, Cambridge, MA). The resulting sequences were screened for data quality, and chloroplast 
sequences were identified and excluded by comparing the sequences to the NCBI nonredundant nucleotide database using BLAST (Altschul et al. 1990). Primer-probe assays were designed using the Universal Probe Library (UPL) Assay Design Center (Roche Diagnostics, Pleasanton, CA). Each DNA marker contained a primer set that amplified a small PCR product (80-120 bp) and a UPL MGB probe containing a 5' FAM fluorescent dye and a 3' dark quencher dye (Table 1).

All potential DNA markers were evaluated for species-specificity and reliability for estimating species ratios in root samples. First, each marker was tested on DNA from each of the three species in the current study as well as three others that are routinely used in our experiments (Dianthus armeria, Bromus inermis, and Schizachyrium scoparium), and was considered species-specific if it produced signal with DNA from the target species and no signal with DNA from non-target species. Additionally, we tested the markers on samples containing known mixtures of DNA (50:50 and 10:90 target to non-target species) to ensure that amplification was not affected by the presence of non-target DNA. Finally, we extracted DNA from artificially mixed root samples (total $25 \mathrm{mg}, \pm 0.5 \mathrm{mg}$ ) with known fresh weights of target and nontarget species to determine the accuracy and precision of the relationship between fresh weight percentage and estimated percentage by qPCR. Samples containing 1:9, 1:3, 1:1, 3:1, and 9:1 fresh weights of target species root tissue were made for all pairs of species.

All qPCR was performed using a Lightcycler 480 (Roche Diagnostics). Each sample was run in duplicate, including negative controls. To calculate amplification efficiency, a standard curve was run in triplicate consisting of a four-point, 1:4 serial dilution of a pure sample of root DNA from the target species. The qPCR profile was as follows: $95^{\circ} \mathrm{C}$ for 3 minutes, followed by 45 cycles of $95^{\circ} \mathrm{C}$ for 15 seconds and $60^{\circ} \mathrm{C}$ for 1 minute. Each $20 \mu \mathrm{l}$ reaction contained $1 \mu \mathrm{M}$ of each primer, $0.1 \mu \mathrm{M}$ UPL MGB probe (Roche), and PrimeTime Gene Expression Master Mix (Integrated DNA Technologies, Skokie, IL). For samples of mixed DNA (50:50 and 10:90), the total DNA added to each reaction varied proportionally so that the target amount of DNA stayed constant at 10ng. For samples of artificially mixed roots and all unknown samples, $10 \mathrm{ng}$ of total DNA was added to each reaction.

\section{Experimental design}

The greenhouse experiment used square pots (12.7 cm x $16.5 \mathrm{~cm}$ deep; Fig. 1) in which one quadrant was home to a focal Plantago seedling and the opposite quadrant was home to a Centaurea neighbor, a Poa neighbor, or no neighbor. The two remaining quadrants were designated "away" quadrants. Soil resources in each pot were evenly distributed, with resource availability equal in all quadrants, or heterogeneously distributed, with resource availability higher in one of the two away quadrants and lower in the remaining three quadrants. Neighbor treatments and soil treatments were fully crossed, with ten replicates per treatment, for a total of 60 pots ( 3 neighbors $\times 2$ soils $\times 10$ replicates).

Resource distribution was manipulated by creating different mixtures of commercial play sand and compost (Just Natural Mushroom Compost, Oldcastle Lawn and Garden, Poland Spring, ME) in varying ratios. Pots with even resources were filled with a mixture of $80 \%$ sand and $20 \%$ compost by volume. To create patchy soil resources, pots were divided into quadrants with plastic barriers. One quadrant was 
filled with $50 \%$ sand $/ 50 \%$ compost, and the remaining three quadrants were filled with $90 \%$ sand $/ 10 \%$ compost. Barriers between quadrants were removed after filling. Total resource availability was the same in both soil treatments. We did not attempt to manipulate or test for presence of soil microbes, including mycorrhizal fungi.

Seeds collected on campus of all three study species were sown in in trays filled with $80 \%$ sand $/ 20 \%$ compost and transplanted into pots three weeks after germination. A single Plantago seedling was planted in the center of the focal home quadrant of each pot. A single seedling of either Centaurea or Poa was planted in the center of the neighbor home quadrant, or the neighbor quadrant was left empty, to create the three neighbor treatments.

\section{Harvest and data collection}

Seedlings were planted on 29 July 2015 and grew for approximately 50 days. The pots were harvested over six days so that harvested roots could be promptly preserved for DNA extraction. Ten pots had one or more plants die during the experiment and were not used for analysis, leaving three replicates with Poa neighbors in even soil, and 8-10 replicates of each remaining treatment. At the time of harvest, aboveground biomass was cut with scissors at the base of the plant and dried at $80^{\circ} \mathrm{C}$ for 48 hours before weighing. Soil from away quadrants was removed and left to air dry for 1-2 hours in order to easily sift out roots. Roots were patted dry and weighed fresh before being put in $1.5 \mathrm{~mL}$ microcentrifuge tubes and stored at $-80^{\circ} \mathrm{C}$ until DNA was extracted. Because isolating roots from soil was time consuming, and harvested roots needed to be preserved while fresh, roots were not collected from home quadrants.

For pots with neighbors, DNA was extracted from the entire root sample from each away quadrant. Quantitative PCR was conducted with a Lightcycler 480 Real-Time PCR System (Roche Diagnostics, Pleasanton, CA), using DNA markers designed for each species, as described above. All samples were run in duplicate for each species in each sample (4 qPCR reactions per root sample). A 1:4 serial dilution standard curve done in triplicate was included for each species, and reference samples with known ratios of each species DNA were included for quality control.

Unknown samples were standardized relative to 1:1 reference samples, following the approach used by Mommer et al. (2008). Twenty reference samples were made for each species pair by combining $25 \mathrm{mg}$ $( \pm 0.5 \mathrm{mg})$ of fresh root tissue from each species. DNA was extracted as described above. Relative species proportions in test samples were calculated from raw $\mathrm{Ct}$ values and reference values using formulas from Mommer et al. (2008) and then multiplied by the total root mass in each away quadrant to determine the root mass from each species.

\section{Data analysis}

The effects of experimental treatments on root growth were tested with ANOVA, with summed root mass in the two away quadrants as the response variable, and with soil environment (even or patchy), neighbor identity (none, Centaurea, or Poa) and their interaction included as fixed factors. Shoot mass of the focal 
plant was included as a covariate, so that treatment effects on root mass reflected changes in allocation, rather than absolute biomass. To interpret a significant interaction term, we used posthoc pairwise comparisons of neighbor treatments within each soil treatment.

In pots with heterogeneous soil, root allocation between the high-resource and low-resource away quadrants was analyzed with mixed-effects ANOVA, with focal root mass within a quadrant as the response variable, focal shoot mass as a covariate, neighbor treatment as a between-subjects factor, and quadrant as a within-subjects factor. To interpret a significant interaction term, we used posthoc pairwise comparisons of neighbor treatments within each quadrant. To test for foraging precision, we used pairwise comparisons of quadrants within each neighbor treatment.

To compare potential competitive effects of the two neighbor species, two-way ANOVA was used to test for effects of soil environment, neighbor species, and their interaction on total neighbor root mass in the two away quadrants. Neighbor shoot mass was not included as a covariate, because the value of interest was neighbor root abundance, not allocation.

Analyses were completed with R statistical software, version 4.0.0 (R Core Team 2020). Root and shoot mass values were natural log transformed to improve normality and homogeneity of variance. ANOVAs with mixed effects were fitted with the 'Ime4' package (Bates et al. 2015). Model siginficance was evaluated with Type III sums of squares with the package 'car' (Fox and Weisberg 2019). Posthoc comparisons were tested with the 'emmeans' package, using Tukey's method to adjust for multiple comparisons (Length 2020).

\section{Results}

\section{Marker development and validation}

Each DNA marker had acceptable qPCR efficiencies across a 64-fold range of DNA concentrations, indicating that amplification was consistent regardless of the amount of initial DNA. Moreover, amplification was not affected by the addition of equal $(50 \%)$ or large $(90 \%)$ relative amounts of DNA from non-target species. Finally, as expected, there was no amplification signal in samples lacking the target species, such as samples containing only DNA from non-target species and negative controls. The estimated percentages of target species were highly correlated with the initial fresh weight percentages for each species (Fig. 2), indicating that these markers can accurately predict the starting fresh weight for a target species using qPCR. For example, Poa fresh weight estimates based on qPCR ranged from 87$90 \%$ for $9: 1$ reference samples, $9-16 \%$ for $1: 9$ reference samples, and $37-65 \%$ for $1: 1$ reference samples. DNA markers for Centaurea and Plantago had more variation in estimated percentages, but all were well within acceptable ranges (Fig. 2). Each regression had an $\mathrm{R}^{2}$ of 0.80 or better and relatively narrow confidence and prediction intervals (Fig. 2), comparable to that of Mommer et al. (2008). Based on these findings, we were satisfied that the DNA markers were species-specific and reliable for quantification of relative species abundances in mixed root samples. 
Root allocation of the focal plant to shared quadrants depended on the soil environment and neighbor treatment (significant interaction term, Table 2). Plantago produced about twice as much root mass in away quadrants with a Centaurea neighbor than when grown alone in either soil type (Fig. 3). With a Poa neighbor, Plantago produced about four times as much root mass, but only when soil was patchy (Fig. 3). Shoot biomass was a significant covariate for root mass (Table 2), but when analyzed separately, Plantago shoot biomass was not affected by soil environment or neighbor treatment (results not shown).

In pots with patchy soil, Plantago's root distribution between shared quadrants depended on the neighbor treatment (significant interaction term, Table 3). With a Centaurea neighbor, Plantago increased root mass in the high-resource quadrant but not in the low-resource quadrant. With a Poa neighbor, Plantago increased root mass in both low and high resource quadrants (Fig. 4). Without a neighbor, root mass was

similar in the two quadrants, indicating no foraging precision. With a neighbor present, Plantago exhibited foraging precision, producing significantly more roots in the high-resource quadrant (Fig. 4).

Although Centaurea neighbors tended to have greater root mass in shared soil than Poa neighbors (Fig. 5), neighbor root mass was highly variable and not significantly affected by species or soil environment (Table 4).

\section{Discussion}

Root growth of Plantago lanceolata responded to both neighbors and resources. As predicted, root growth in shared soil increased in the presence of a neighbor. When resource levels varied in the shared soil, Plantago showed a stronger response to neighbors where resources were high, resulting in increased foraging precision. These responses differed between two neighbor species, with a stronger response to Centaurea when soil resources were evenly distributed and a stronger response to Poa when resources had a patchy distribution..

\section{Neighbor detection and discrimination}

When a neighbor was present in the pot, Plantago allocated more root biomass to the "away" quadrants of the pot than when alone. This increased allocation could reflect either an overall increase in root mass, or a shift in placement of roots. We were unable to distinguish these alternatives because we did not measure root production in the home quadrant. In one previous study, Plantago increased allocation to roots in intraspecific competition (Berendse and Möller 2009), but in other studies it decreased allocation to roots (Janeček et al. 2014) or made no change in allocation (Robinson et al. 2010) in interspecfic competition.

The signal that triggers a shift in either allocation or root placement might be nutrient depletion by the neighbor or direct detection of the neighbor through root exudates (Pierik et al. 2013). Given the short duration of our experiment (seven weeks), depletion of nutrients was unlikely to be important. There was 
no evidence of decreased biomass due to resource competition. Similar overproduction responses to neighbors have been observed in nutrient-rich and nutrient-poor soil (Mommer et al. 2010), demonstrating that the response to neighbors was not dependent on nutrient depletion. Root growth responses have also been observed when root exudates from potential neighbors are added to the soil, even though the neighbors themselves are absent (Biedrzycki et al. 2010; Semchenko et al. 2014).

We found that Plantago's root growth response to Centaurea neighbors was different from its response to Poa neighbors. Species-specific responses to neighbors appear to be common, but not universal. Among a set of 20 co-occuring species, each grown alone or with one of two neighbors, twelve species shifted root growth toward or away from a neighbor, changed rooting depth, changed allocation to roots, or had some combination of responses (Belter and Cahill 2015). These responses differed between the two neighbors. In an experiment comparing root distribution responses to four neighbors, only one of two focal species showed species-specific responses (Sattler and Bartelheimer 2018). Two recent studies that each compared only two neighbor species concluded that neighbor identity does not influence root responses (e.g. Paya et al. 2015; Jacob et al. 2017).

A model of root growth in competition experiments (McNickle and Brown 2012) proposes traits that may drive species-specific responses. The model predicts that when two competitors differ in foraging efficiency, the individual with the higher nutrient uptake rate and/or lower cost of roots will produce more root than it would alone. The optimal strategy for the less efficient individual is to produce less root than it would alone. Comparisons of specific root length and root nitrogen content (data from SchroederGeorgi et al. 2016; Herz et al. 2017; Garlick 2016) suggest that Poa may have a lower cost of root production than Plantago, while Centaurea may have a higher cost. When soil resources were evenly distributed, Plantago behaved as predicted, increasing root growth with Centaurea but not Poa. However, Plantago responded strongly to Poa when resources were concentrated in one quadrant of the pot. With only one focal species and two neighbor species, we are unable to draw generalizable conclusions about the relationship between plant traits and root responses to neighbors.

Other studies have had limited success in identifying traits associated with responses to neighbors. Responses were not predicted by traits related to size, habitat occupancy, or root architecture in the set of 20 species tested by Belter and Cahill (2015). Sattler and Bartelheimer (2018) hypothesized that roots of non-legumes would grow towards a legume neighbor, especially when nitrogen was limiting, but found only one species combination for which that was true. In another study, a perennial grass shifted its rooting depth profile in response to the growth habit of its neighbor, growing progressively deeper with a tree, a shrub, and a perennial forb (Chen et al. 2020).

\section{Integrating information about neighbors and resources}

Plantago's responses to neighbors were also affected by resource heterogeneity. Plantago overproduced roots with a Centaurea neighbor to a similar degree in both even and patchy soil, but when soil was patchy, all of the increased root growth occurred in the resource-rich patch. Plantago responded to a Poa neighbor only when resources were patchy. This specificity suggests that the benefit of pre-empting a 
volume of soil depends on the resources available there and on the identity of the competitor for the space, and that the effects of those factors may be non-additive. In a mixture of four grassland species, the effect of neighbors on root production was also dependent on resource heterogeneity (McNickle et al. 2016). Mixtures produced more roots than expected based on root growth of single plants, but only when resources were heterogeneous, and only in background soil, not in patches. In another study, the foraging strategies of two species responded to neighbors, resource heterogenity, and a third cue, presence of earthworms (Wang et al. 2020).

We found that Plantago did not forage precisely in patchy soil when grown alone but did so when a neighbor was present. A larger study of eight species, including Plantago, Centaurea, and Poa, also observed changes in precision with different competitors (Ravenek et al. 2016). Shifts in precision may help explain why precision measured on isolated individuals is often unrelated to competitive outcomes in heterogeneous soil (e.g. Cahill and Casper 1999; Rajaniemi 2007).

\section{Conclusion}

The ability to integrate multiple cues into an appropriate response is crucial to maintaining a root strategy that is beneficial in many environmental and competitive contexts (Cahill and McNickle 2011). Our results are consistent with others (Cahill et al. 2010; Mommer et al. 2012; Nan et al. 2013; McNickle et al. 2016) in concluding that plants can change their responses depending on the combination of cues they experience. In addition, the integrated response to resources and neighbors incorporates not just the presence of a neighbor, but the identity of the neighbor. More comprehensive experiments involving a large sets of species are needed to elucidate the functional traits that underlie these differential responses.

\section{Declarations}

\section{Acknowledgements}

We wish to thank the undergraduate research students who contributed to development of molecular markers and to greenhouse work and data collection: Cynthia Chude, Corey Exime, Kristofer Gomes, Haim Moore, and Michelle Vanasse.

Funding: This research was funded by National Science Foundation grant DEB-1256942.

Conflicts of interest/Competing interests: The authors have no relevant financial or non-financial interests to disclose.

Availability of data and material: Data have been submitted to Dryad and will be made publicly available upon publication. https://doi.org/10.5061/dryad.47d7wm3cr

Code availability: Not applicable. 
Authors' contributions: All authors contributed to the study conception and design. Experimental methods and data collection were performed by Kelsey Garlick. Data analysis was performed by Kelsey Garlick and Tara Rajaniemi. The first draft of the manuscript was written by Kelsey Garlick and all authors commented on previous versions of the manuscript. All authors read and approved the final manuscript.

\section{References}

Altschul SF, Gish W, Miller W, et al (1990) Basic local alignment search tool. J Mol Biol 215:403-410. https://doi.org/10.1016/S0022-2836(05)80360-2

Bates D, Maechler M, Bolker B, Walker S (2015) Fitting Linear Mixed-Effects Models Using Ime4. J Stat Softw 67:1-48. https://doi.org/10.18637/jss.v067.i01

Belter PR, Cahill JF (2015) Disentangling root system responses to neighbours: identification of novel root behavioural strategies. AoB PLANTS 7:. https://doi.org/10.1093/aobpla/plv059

Berendse F, Möller F (2009) Effects of competition on root-shoot allocation in Plantago lanceolata L.: adaptive plasticity or ontogenetic drift? Plant Ecol 201:567-573. https://doi.org/10.1007/s11258-008$9485-z$

Biedrzycki ML, Jilany TA, Dudley SA, Bais HP (2010) Root exudates mediate kin recognition in plants. Commun Integr Biol 3:28-35. https://doi.org/10.4161/cib.3.1.10118

Cahill JF, Casper BB (1999) Growth consequences of soil nutrient heterogeneity for two old-field herbs, Ambrosia artemisiifolia and Phytolacca americana, grown individually and in combination. Ann Bot 83:471-478. https://doi.org/10.1006/anbo.1999.0841

Cahill JF, McNickle GG (2011) The behavioral ecology of nutrient foraging by plants. Annu Rev Ecol Evol Syst 42:289-311. https://doi.org/10.1146/annurev-ecolsys-102710-145006

Cahill JF, McNickle GG, Haag JJ, et al (2010) Plants integrate information about nutrients and neighbors. Science 328:1657. https://doi.org/10.1126/science.1189736

Chen BJW, During HJ, Anten NPR (2012) Detect thy neighbor: identity recognition at the root level in plants. Plant Sci 195:157-167. https://doi.org/10.1016/j.plantsci.2012.07.006

Chen BJW, Xu C, Liu M-S, et al (2020) Neighbourhood-dependent root distributions and the consequences on root separation in arid ecosystems. J Ecol 108:1635-1648. https://doi.org/10.1111/1365-2745.13360

Craine JM, Dybzinski R (2013) Mechanisms of plant competition for nutrients, water and light. Funct Ecol 27:833-840. https://doi.org/10.1111/1365-2435.12081

de Kroon H, Visser EJW, Huber $\mathrm{H}$, et al (2009) A modular concept of plant foraging behaviour: the interplay between local responses and systemic control. Plant Cell Environ 32:704-712. 
https://doi.org/10.1111/j.1365-3040.2009.01936.x

Fox J, Weisberg S (2019) An \{R\} Companion to Applied Regression, Third Edition. Sage, Thousand Oaks, CA

Fransen B, de Kroon H, Berendse F (2001) Soil nutrient heterogeneity alters competition between two perennial grass species. Ecology 82:2534-2546. https://doi.org/10.1890/0012-

9658(2001)082[2534:SNHACB]2.0.C0;2

Garlick KE (2016) Understanding the effects of environmental and competitive cues on plant root foraging strategies and plant competition. Masters Thesis, University of Massachusetts Dartmouth

Gersani M, Brown JS, O'Brien EE, et al (2001) Tragedy of the commons as a result of root competition. J Ecol 89:660-669. https://doi.org/10.1046/j.0022-0477.2001.00609.x

Grime JP (2007) The scale-precision trade-off in spatial resource foraging by plants: restoring perspective. Ann Bot 99:1017-1021. https://doi.org/10.1093/aob/mcm026

Grime JP, Mackey JML (2002) The role of plasticity in resource capture by plants. Evol Ecol 16:299-307. https://doi.org/10.1023/A:1019640813676

Guerrero-Ramirez N, Mommer L, Freschet GT, et al (2020) Global Root Traits (GRooT) Database. bioRxiv 2020.05.17.095851. https://doi.org/10.1101/2020.05.17.095851

Hendriks M, Visser EJW, Visschers IGS, et al (2015) Root responses of grassland species to spatial heterogeneity of plant-soil feedback. Funct Ecol 29:177-186. https://doi.org/10.1111/1365-2435.12367

Herz K, Dietz S, Haider S, et al (2017) Drivers of intraspecific trait variation of grass and forb species in German meadows and pastures. J Veg Sci 28:705-716. https://doi.org/10.1111/jvs.12534

Hodge A (2004) The plastic plant: root responses to heterogeneous supplies of nutrients. New Phytol 162:9-24. https://doi.org/10.1111/j.1469-8137.2004.01015.x

Jacob CE, Tozzi E, Willenborg CJ (2017) Neighbour presence, not identity, influences root and shoot allocation in pea. PLOS ONE 12:e0173758. https://doi.org/10.1371/journal.pone.0173758

Janeček S, Patáčová E, Klimešová J (2014) Effects of fertilization and competition on plant biomass allocation and internal resources: does Plantago lanceolata follow the rules of economic theory? Folia Geobot 49:49-64. https://doi.org/10.1007/s12224-013-9161-5

Johnson HA, Biondini ME (2001) Root morphological plasticity and nitrogen uptake of 59 plant species from the Great Plains grasslands, USA. Basic Appl Ecol 2:127-143. https://doi.org/10.1078/1439-179100044 
Kembel SW, Cahill JF (2005) Plant phenotypic plasticity belowground: a phylogenetic perspective on root foraging trade-offs. Am Nat 166:216-230. https://doi.org/10.1086/431287

Kembel SW, de Kroon H, Cahill JF, Mommer L (2008) Improving the scale and precision of hypotheses to explain root foraging ability. Ann Bot 101:1295-1301. https://doi.org/10.1093/aob/mcn044

Length R (2020) emmeans: Estimated Marginal Means, aka Least-Squares Means. Version R package version 1.4.7URL https://CRAN.R-project.org/package=emmeans

Maestre FT, Reynolds JF (2007) Biomass responses to elevated $\mathrm{CO}_{2}$, soil heterogeneity and diversity: an experimental assessment with grassland assemblages. Oecologia 151:512-520. https://doi.org/10.1007/s00442-006-0577-y

McNickle GG, Brown JS (2014) An ideal free distribution explains the root production of plants that do not engage in a tragedy of the commons game. J Ecol 102:963-971. https://doi.org/10.1111/13652745.12259

McNickle GG, Brown JS (2012) Evolutionarily stable strategies for nutrient foraging and below-ground competition in plants. Evol Ecol Res 14:667-687

McNickle GG, Deyholos MK, Cahill JF (2016) Nutrient foraging behaviour of four co-occurring perennial grassland plant species alone does not predict behaviour with neighbours. Funct Ecol 30:420-430. https://doi.org/10.1111/1365-2435.12508

Mommer L, van Ruijven J, de Caluwe $\mathrm{H}$, et al (2010) Unveiling below-ground species abundance in a biodiversity experiment: a test of vertical niche differentiation among grassland species. J Ecol 98:11171127. https://doi.org/10.1111/j.1365-2745.2010.01702.x

Mommer L, van Ruijven J, Jansen C, et al (2012) Interactive effects of nutrient heterogeneity and competition: implications for root foraging theory? Funct Ecol 26:66-73. https://doi.org/10.1111/j.13652435.2011.01916.x

Mommer L, Wagemaker CAM, de Kroon H, Ouborg NJ (2008) Unravelling below ground plant distributions: a real time polymerase chain reaction method for quantifying species proportions in mixed root samples. Mol Ecol Resour 8:947-953. https://doi.org/10.1111/j.1755-0998.2008.02130.x

Nan H, Liu Q, Chen J, et al (2013) Effects of nutrient heterogeneity and competition on root architecture of spruce seedlings: implications for an essential feature of root foraging. PLoS ONE 8:e65650.

https://doi.org/10.1371/journal.pone.0065650

O'Brien EE, Brown JS (2008) Games roots play: effects of soil volume and nutrients. J Ecol 96:438-446. https://doi.org/10.1111/j.1365-2745.2008.01354.x 
O'Brien EE, Gersani M, Brown JS (2005) Root proliferation and seed yield in response to spatial heterogeneity of below-ground competition. New Phytol 168:401-412. https://doi.org/10.1111/j.14698137.2005.01520.x

Oram NJ, Ravenek JM, Barry KE, et al (2018) Below-ground complementarity effects in a grassland biodiversity experiment are related to deep-rooting species. J Ecol 106:265-277. https://doi.org/10.1111/1365-2745.12877

Padilla FM, Mommer L, de Caluwe $\mathrm{H}$, et al (2013) Early root overproduction not triggered by nutrients decisive for competitive success belowground. PLoS ONE 8:e55805. https://doi.org/10.1371/journal.pone.0055805

Paya AM, Silverberg JL, Padgett J, Bauerle TL (2015) X-ray computed tomography uncovers root-root interactions: quantifying spatial relationships between interacting root systems in three dimensions. Front Plant Sci 6:. https://doi.org/10.3389/fpls.2015.00274

Pierik R, Mommer L, Voesenek LA (2013) Molecular mechanisms of plant competition: neighbour detection and response strategies. Funct Ecol 27:841-853. https://doi.org/10.1111/1365-2435.12010

R Core Team (2020) R: A language and environment for statistical computing. R Foundation for Statistical Computing, Vienna, Austria

Rajaniemi TK (2007) Root foraging traits and competitive ability in heterogeneous soils. Oecologia 153:142-152. https://doi.org/10.1007/s00442-007-0706-2

Ravenek JM, Mommer L, Visser EJW, et al (2016) Linking root traits and competitive success in grassland species. Plant Soil 1-15. https://doi.org/10.1007/s11104-016-2843-z

Robinson D, Davidson H, Trinder C, Brooker R (2010) Root-shoot growth responses during interspecific competition quantified using allometric modelling. Ann Bot 106:921-926. https://doi.org/10.1093/aob/mcq186

Sattler J, Bartelheimer M (2018) Root responses to legume plants integrate information on nitrogen availability and neighbour identity. Basic Appl Ecol 27:51-60.

https://doi.org/10.1016/j.baae.2018.01.001

Schenk HJ, Callaway RM, Mahall BE (1999) Spatial root segregation: are plants territorial? In: A.H. Fitter and D. Raffaelli (ed) Advances in Ecological Research. Elsevier, pp 145-180

Schroeder-Georgi T, Wirth C, Nadrowski K, et al (2016) From pots to plots: hierarchical trait-based prediction of plant performance in a mesic grassland. J Ecol 104:206-218. https://doi.org/10.1111/1365-2745.12489 
Semchenko M, John EA, Hutchings MJ (2007) Effects of physical connection and genetic identity of neighbouring ramets on root-placement patterns in two clonal species. New Phytol 176:644-654. https://doi.org/10.1111/j.1469-8137.2007.02211.x

Semchenko M, Saar S, Lepik A (2014) Plant root exudates mediate neighbour recognition and trigger complex behavioural changes. New Phytol 204:631-637. https://doi.org/10.1111/nph.12930

Vos P, Hogers R, Bleeker M, et al (1995) AFLP: a new technique for DNA fingerprinting. Nucleic Acids Res 23:4407-4414. https://doi.org/10.1093/nar/23.21.4407

Wang P, Hasnain M, Cahill J, Wu D (2020) The multi-response of root foraging strategy to a neighbor, soil heterogeneity and earthworm. Appl Soil Ecol 155:103684. https://doi.org/10.1016/j.apsoil.2020.103684

Wijesinghe DK, John EA, Beurskens S, Hutchings MJ (2001) Root system size and precision in nutrient foraging: responses to spatial pattern of nutrient supply in six herbaceous species. J Ecol 89:972-983. https://doi.org/10.1111/j.1365-2745.2001.00618.x

\section{Tables}

Table 1

Primer sequences and probes used in this study to quantify the abundances of three species using quantitative PCR

\begin{tabular}{|llll|}
\hline Species & $\begin{array}{l}\text { UPL } \\
\text { probe } \\
\#\end{array}$ & $\begin{array}{l}\text { Marker } \\
\text { Name }\end{array}$ & Primers \\
\hline $\begin{array}{l}\text { Plantago } \\
\text { lanceolata }\end{array}$ & 46 & Pla44 & 5'-TGAGTCTAGAACGGGGATGTTT-3' \\
\hline $\begin{array}{l}\text { Centaurea } \\
\text { jacea }\end{array}$ & 75 & Cen54 & 5'-AGCGGTGGTAGAAGAGCTTG-3' \\
\hline $\begin{array}{l}\text { Poa pratensis } \\
\text { 147 }\end{array}$ & Ppr49 & 5'-CAACAAAATCTGGTCAGAATGC-3' \\
\hline
\end{tabular}


Table 2

ANOVA results for root mass of Plantago focal plants summed over two away quadrants. Root mass and shoot mass were natural log transformed for analysis

\begin{tabular}{|llll|}
\hline Source of variation & $\mathbf{F}$ & df & P \\
\hline shoot mass & 46.53 & 1,43 & $<0.001$ \\
\hline neighbor & 6.42 & 2,43 & 0.004 \\
\hline soil & 0.04 & 1,43 & 0.851 \\
\hline neighbor x soil & 5.07 & 2,43 & 0.011 \\
\hline
\end{tabular}

Table 3

ANOVA results for root mass of Plantago focal plants in highresource and low-resource quadrants, for the patchy soil environment only. Root mass and shoot mass were natural log transformed for analysis

\begin{tabular}{|llll|}
\hline Source of variation & $\boldsymbol{\chi}^{2}$ & $\mathbf{d f}$ & $\mathbf{P}$ \\
\hline shoot mass & 12.79 & 1 & $<0.001$ \\
\hline neighbor & 9.16 & 2 & 0.010 \\
\hline quadrant & 0.12 & 1 & 0.724 \\
\hline $\begin{array}{l}\text { neighbor } x \\
\text { quadrant }\end{array}$ & 10.41 & 2 & 0.005 \\
\hline
\end{tabular}

Table 4

ANOVA results for root mass of neighbor plants summed over two away quadrants. Root mass was natural log transformed for analysis

\begin{tabular}{|llll|}
\hline Source of variation & $\mathbf{F}$ & $\mathbf{d f}$ & $\mathbf{P}$ \\
\hline neighbor species & 2.81 & 1,26 & 0.106 \\
\hline soil & 0.40 & 1,26 & 0.535 \\
\hline $\begin{array}{l}\text { neighbor species } \mathrm{x} \\
\text { soil }\end{array}$ & 0.11 & 1,26 & 0.742 \\
\hline
\end{tabular}




\section{even}
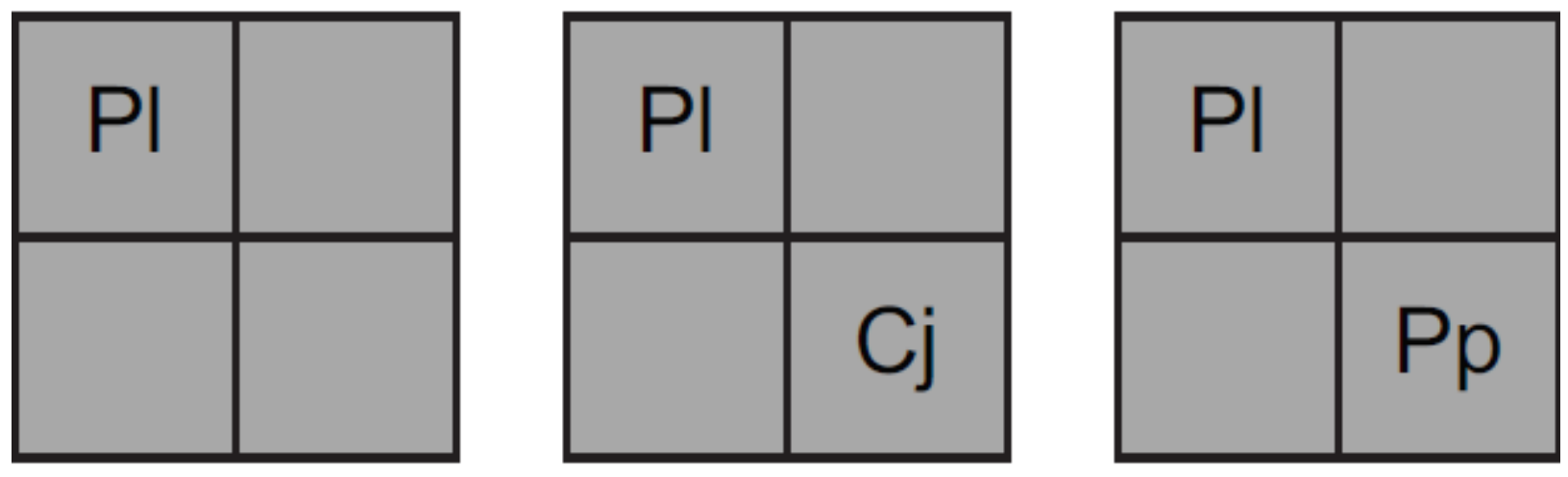

\section{patchy}
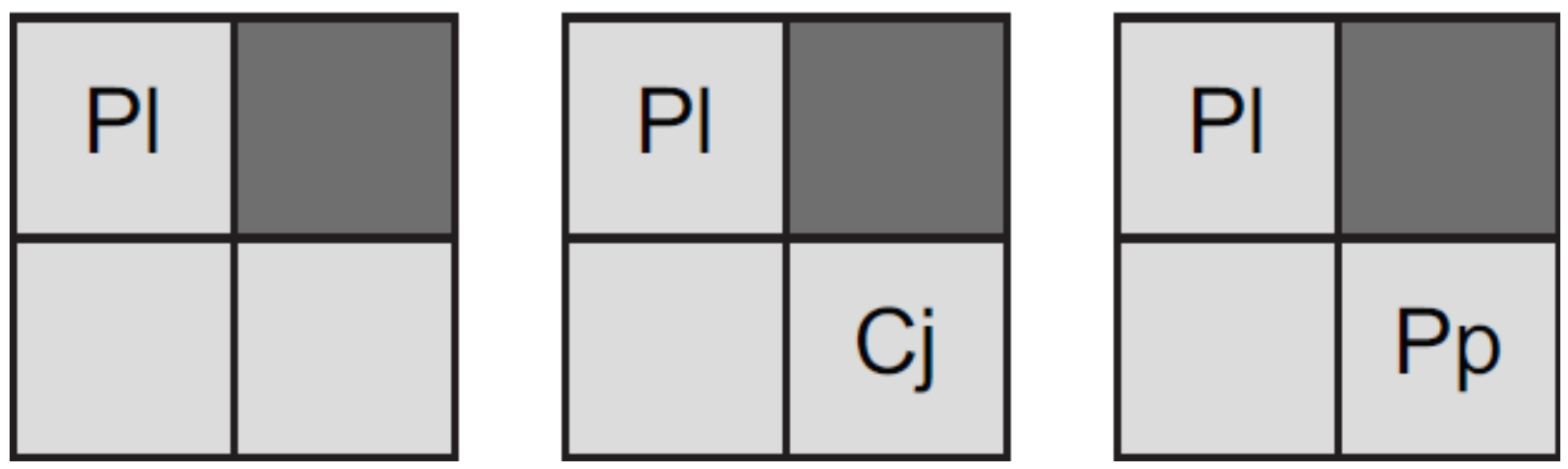

Figure 1

Experimental design. Each pot was divided into four quadrants, without barriers between quadrants.

Resource levels are indicated by darkness of shading. Even pots had equal resource availability in all four quadrants; patchy pots had high resource availability in one quadrant. Each pot had a focal Plantago plant (PI) with no neighbor, a Centaurea (Cj) neighbor, or a Poa (Pp) neighbor
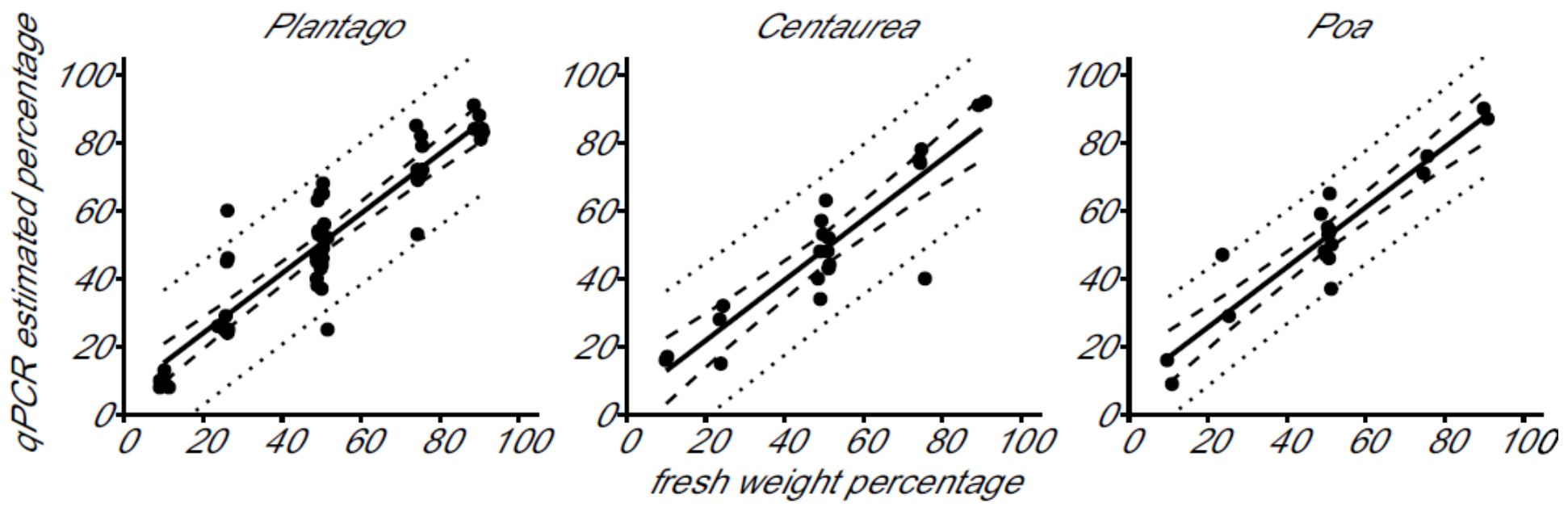

Figure 2 
Regression of estimated species percentage versus fresh weight species percentage for known root mixtures. The dashed lines indicate the $95 \%$ confidence interval; dotted lines indicate the $95 \%$ prediction interval

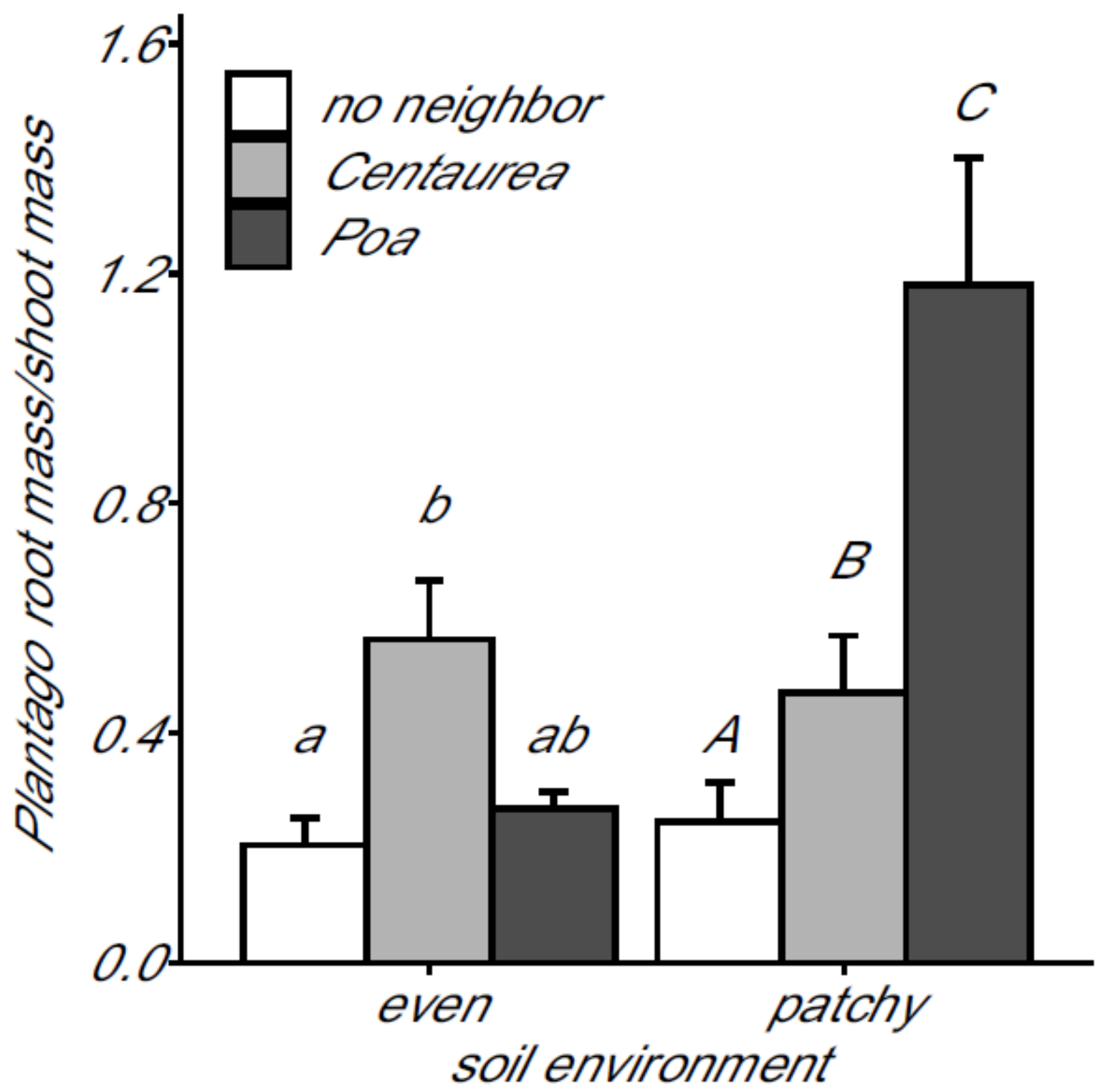

Figure 3

Root mass of Plantago focal plants in two away quadrants combined, divided by shoot mass, in three neighbor treatments and two soil environments. Root mass was estimated using qPCR in treatments with neighbors and measured directly in the treatment with no neighbors. Effects of treatments on root mass were analyzed with shoot mass as a covariate. Different letters indicate significant difference $(p<0.01)$ between neighbor species within a soil treatment. For pots with no neighbor, $\mathrm{n}=10$ for both soils; Centaurea neighbor, $\mathrm{n}=10$ and 8 for even and patchy soils; Poa neighbor, $\mathrm{n}=3$ and 9 


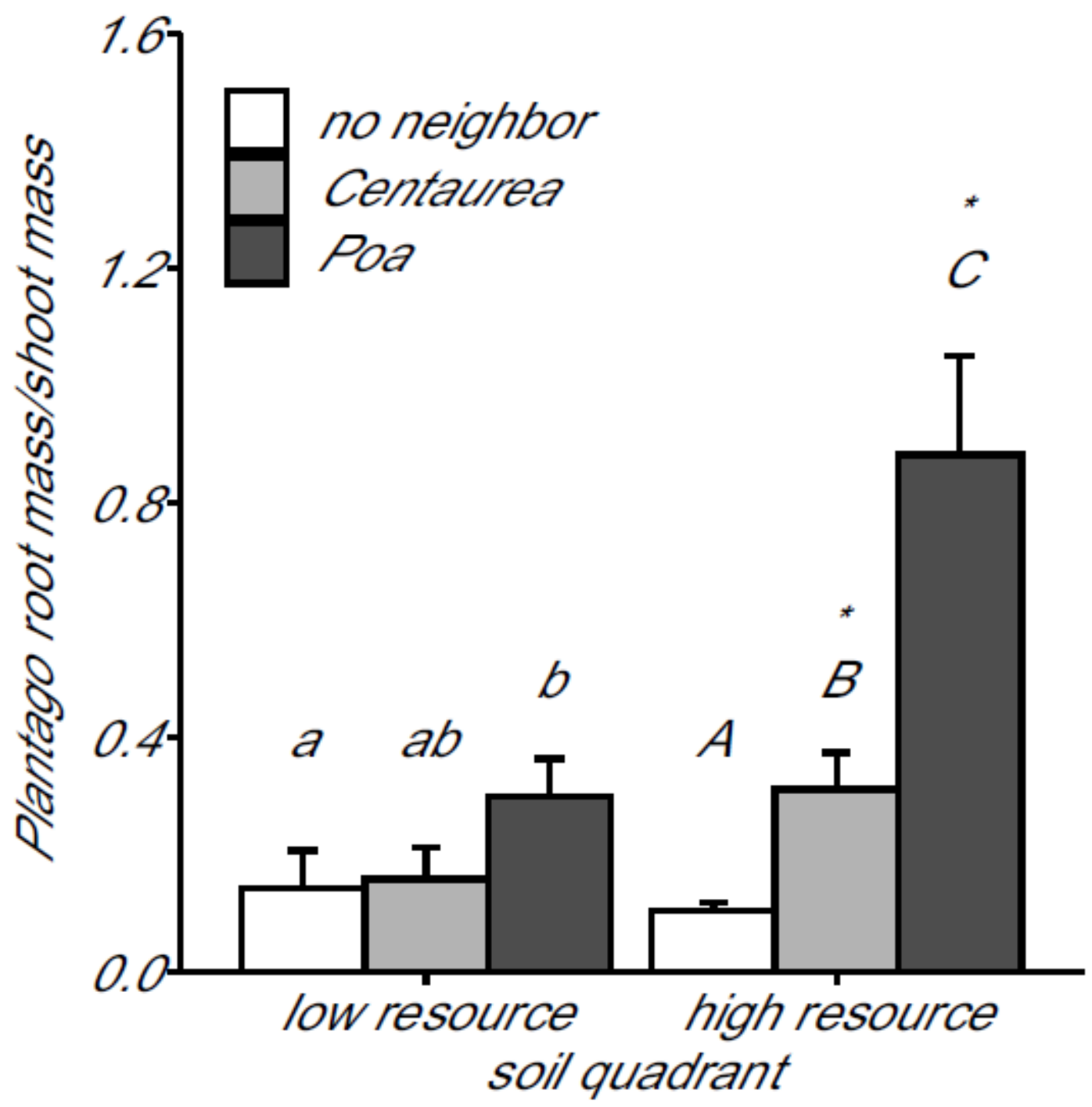

Figure 4

Root mass of Plantago focal plants in the low- and high-resource away quadrants, divided by shoot mass, in three neighbor treatments. Root mass was estimated using qPCR in treatments with neighbors and measured directly in the treatment with no neighbors. Data are for the patchy soil environment only. Effects of treatments on root mass were analyzed with shoot mass as a covariate. Different letters indicate significant differences $(p<0.05)$ between neighbor species within a quadrant type. Stars indicate that root mass differs significantly $(p<0.01)$ between the two quadrants within a neighbor treatment. Samples sizes as in Fig. 2 


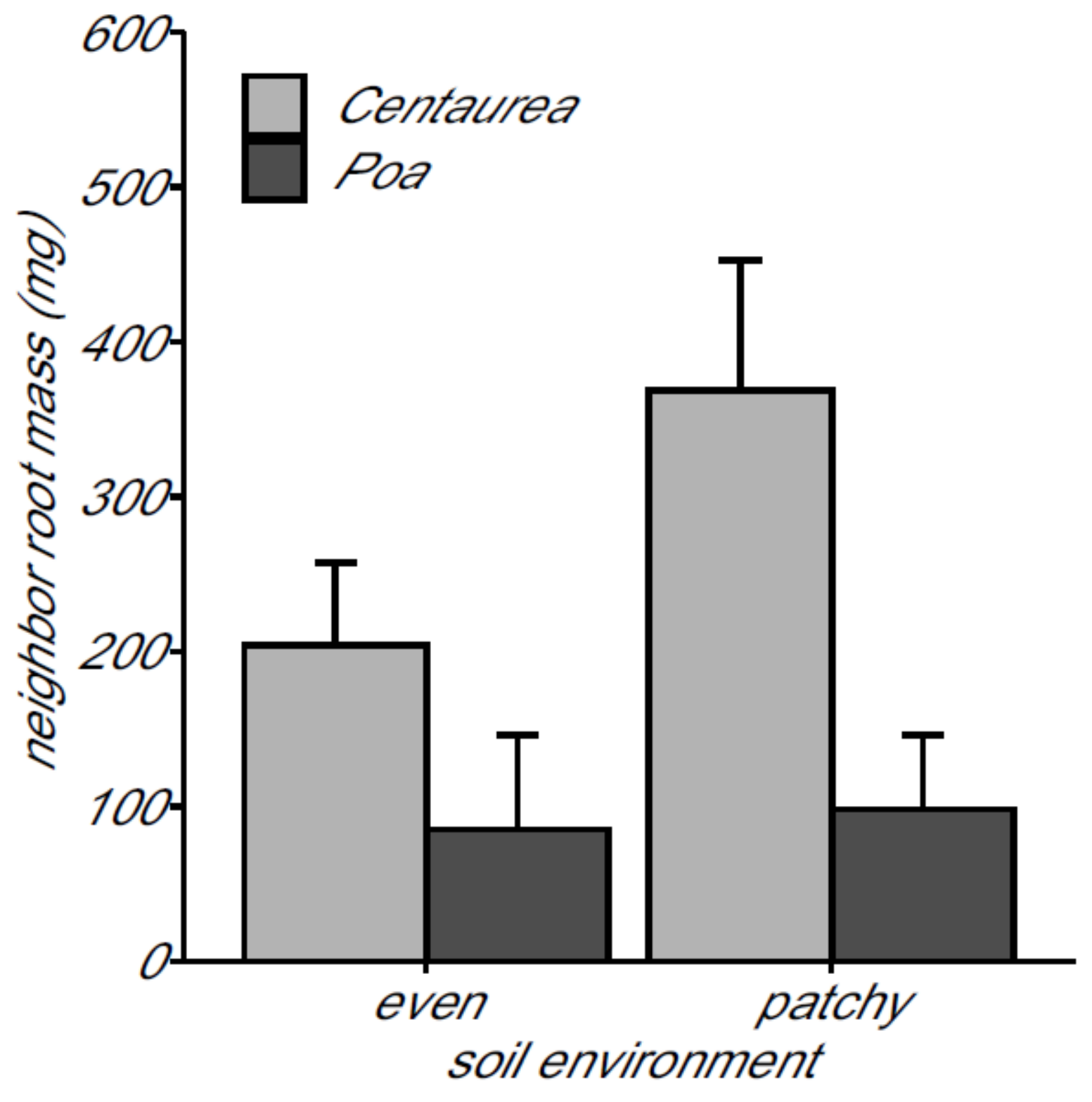

Figure 5

Root mass estimated by qPCR in two away quadrants combined of Centaurea and Poa neighbors plants, in two soil environments. Sample sizes as in Fig. 2 